\title{
Lower motor neuron degeneration and familial predisposition to colonic neoplasia in two adult siblings
}

\author{
Pamela J Shaw, Paul G Ince, Janet Slade, John Burn, Niall E F Cartlidge
}

\begin{abstract}
A previously unreported association between a familial predisposition to colonic neoplasia and familial adult onset lower motor neuron (LMN) degeneration is reported. Two brothers presented at the ages of 53 and 44 years with multiple colonic adenomata and invasive colonic carcinoma respectively. Subsequently both developed a virtually identical pattern of motor neuron disease of progressive muscular atrophy type. At presentation both had LMN weakness affecting predominantly the upper limb and neck muscles. The disease progressed rapidly to involve the lower limb and bulbar musculature and both brothers died after a 15 month course. Necropsy was performed on one brother and showed pathological changes confined to the LMNs with no evidence of involvement of the pyramidal tracts or motor cortex. The combination of these diseases in two brothers may be of importance in the search for genes responsible for familial motor neuron disorders. It is suggested that a genomic search should be directed initially to the vicinity of known colon neoplasia genes, particularly $5 q, 17 q$ and $18 q$.
\end{abstract}

University of

Newcastle upon Tyne, Newcastle upon Tyne, Department of Neurology P J Shaw

NE F Cartlidge

Department of Pathology

PG Ince`

Department of

Human Genetics

J Burn

MRC Neurochemical Pathology Unit, * Newcastle upon Tyne, UK

J Slade

Correspondence to: Dr Shaw, Department of Neurology, Ward 6, Royal Victoria Infirmary, Newcastle upon Tyne NE 4LP, UK

Received 21 December 1990 and in revised form 15 March 1991.

Accepted 26 March 1991
The existence of the familial form of adult motor neuron disease (MND) and its probable genetic basis has only been widely recognised since the report of Kurland and Mulder in 1955. ${ }^{1}$ Individuals with familial disease may represent $5-10 \%$ of cases. It is likely, however, that the incidence of familial MND is underestimated when the diagnosis is based on routine clinical history. The late onset, short duration, low incidence and reduced penetrance of MND to document and that some familial cases may appear sporadic. ${ }^{2}$ Many or even most cases of MND may have a genetic basis. ${ }^{3}$ Adult onset familial MND is usually inherited as an autosomal dominant trait, often with reduced penetrance. Occasional cases of possible autosomal recessive inheritance, which may represent examples of gonadal mosaicism, have also been described. ${ }^{4}$

The presence of genetically-determined cases of MND suggest that one or more biomeans that familial aggregation may be difficult chemical defects may permit clinical expression of MND or alternatively that there may be an inherited susceptibility to an environmental cause of motor neuron injury. Identification of the genetic defect in familial MND may lead to elucidation of molecular mechanisms of motor neuron degeneration common to both the familial and sporadic forms of the disease.

It has recently been reported that the genetic defect responsible for both chronic ${ }^{56}$ and acute ${ }^{7}$ childhood-onset spinal muscular atrophy (SMA) maps to the chromosome region $5 \mathrm{q}$ 11.2-14 in close proximity to the gene coding for hexosaminidase B. The important question as to whether adult-onset cases of familial anterior horn cell disease may similarly map to chromosome $5 \mathrm{q}$ clearly needs to be addressed.

The genetic defect responsible for familial adenomatous polyposis coli (APC) has been localised to the q21-22 region of chromosome $5 .^{8}$ More recently Leppert et al have shown that mutations at the genetic locus for APC may be the cause of other, more subtle syndromes involving an inherited susceptibility to colonic adenomatous polyps or colorectal cancer. ${ }^{9}$ Members of the kindred described in the latter report were characterised by a relatively small number of adenomatous polyps and by a susceptibility to early-onset colonic cancer. The authors suggest that there is a diversity of APC alleles resulting in a variable predisposition to colonic neoplasia.

We describe two brothers who had a virtually identical pattern of the progressive muscular atrophy (PMA) type of MND and also a familial predisposition to colonic neoplasia.

\section{Case reports \\ Case 1}

A 58 year old man presented in 1988 with a 12 month history of progressive wasting and weakness of both upper limbs, the right side being affected to a greater extent. For three months he had noticed difficulty in holding his head upright and mild proximal weakness in the lower limbs. In his past history he had developed hypertension at the age of 40 years, for which he was treated with atenolol. Between 1981-85 endoscopic polypectomies were performed on three occasions for adenomatous polyps of the colon and rectum. On the first occasion a benign tubular adenoma of the rectum was removed. In 1983 a moderate sized 
adenomatous polyp was removed from the ascending colon. In 1985 a further adenomatous polyp was removed from the rectum. Sigmoidoscopy at that time showed no other lesions in the rectum or sigmoid colon, but the more proximal colon was not examined.

General medical examination was unremarkable. On neurological examination widespread wasting and fasciculations were observed in the limb muscles. The trunk and neck muscles were moderately weak. In the upper limbs there was global weakness, more marked on the right than the left, and affecting the proximal more than the distal muscles. There were no sensory abnormalities, the tendon reflexes were normal and both plantar responses were flexor. No upper motor neuron features were noted and the clinical diagnosis was of motor neuron disease (progressive muscular atrophy type).

Routine haematological and biochemical investigations were normal except for a creatine kinase level of $398 \mathrm{u} / \mathbf{l}$ (normal $<175 \mathrm{u} / \mathrm{l}$ ). Borrelia titres and serum lead levels were normal. Detailed neurophysiological testing showed changes consistent with diffuse anterior horn cell dysfunction. The CSF contained $6 \mathrm{WBC} / \mu \mathrm{l}$ and a protein level of $0.56 \mathrm{~g} / 1$ $(0 \cdot 2-0 \cdot 5 \mathrm{~g} / \mathrm{l})$.

The patient's condition inexorably deteriorated and he died of respiratory failure 15 months after presentation. The relatives refused permission for necropsy examination. It is therefore uncertain whether any further
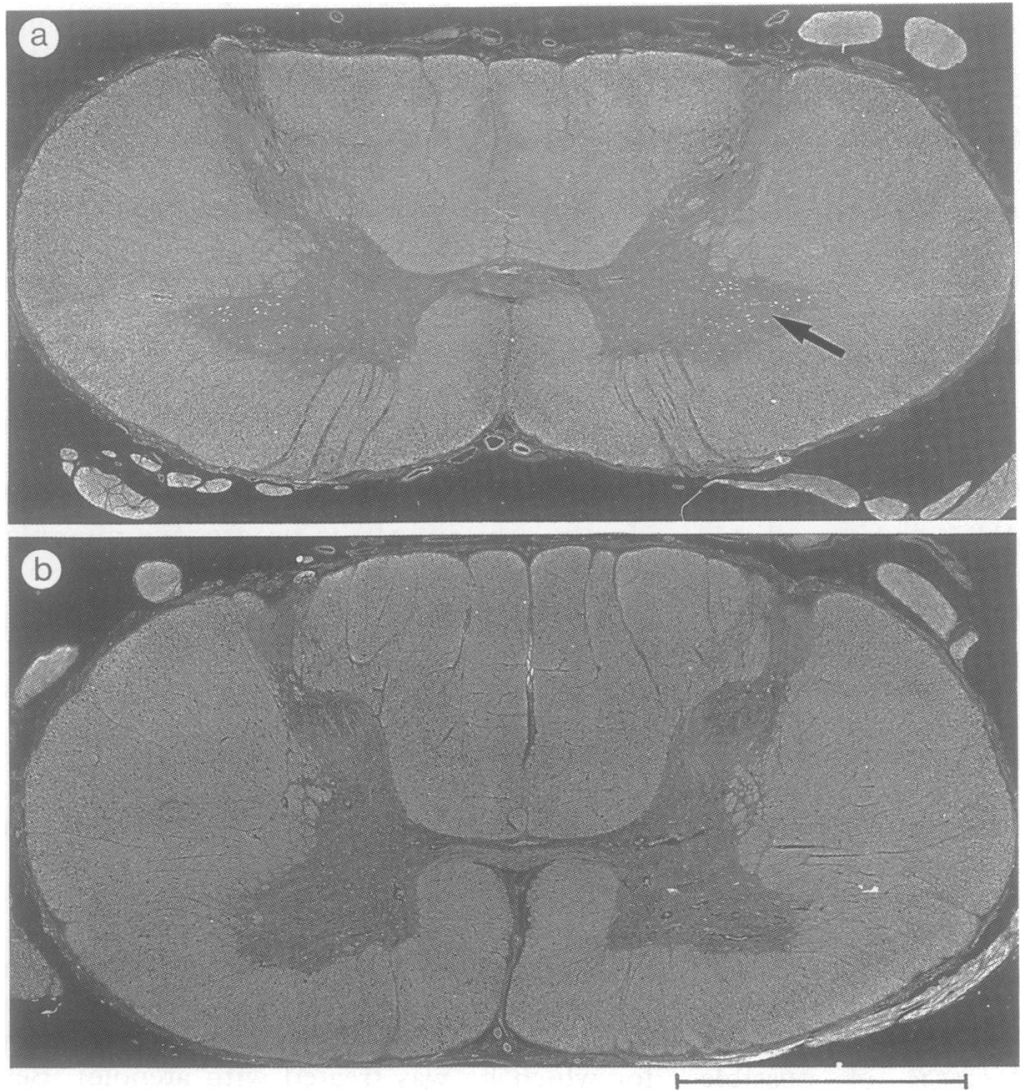

Figure 1 Negative image of the C6 section of the spinal cord of: A) A neurologically normal control case and $B$ ) case 2 . In the control case there is a normal population of lower motor neurons in the ventral horns (arrowed). In case 2 there is marked depletion of the ventral horn lower motor neuron population with an absence of pathological change in the corticospinal tracts. (Cresyl violet, Luxol fast blue. Bar =4mm). colonic pathology developed between 1985 and the patient's death in 1989.

\section{Case 2}

The older brother of case 1 presented at the age of 61 years, nine months after his brother had been diagnosed as having motor neuron degeneration. His presenting history was almost identical to that of his brother. There was a 12 month history of progressive weakness and wasting of the right arm. For three months he had been aware of weakness of the left arm and the neck extensors. He was troubled by painful cramps affecting all the muscles. In the past, he had been treated with nifedipine for one year for hypertension. In 1971, at the age of 44 years, he had had a sigmoid colectomy for a Duke's grade $\mathrm{C}$ adenocarcinoma of the colon.

General examination was unremarkable except for mild hypertension. On neurological examination he was unable to extend the neck and there was mild bilateral facial and tongue weakness. There was widespread wasting and fasciculations in the limbs. There was global severe weakness in the upper limbs affecting the right side more than the left. In the lower limbs there was mild weakness of knee flexion bilaterally. The upper limb reflexes were depressed and the ankle jerks were absent. The plantar responses were flexor.

Routine haematological and biochemical investigations were normal except for elevation of the creatine kinase $424 \mathrm{u} / 1(<175 \mathrm{u} / \mathrm{l})$. Autoantibodies, immunoglobulins, serum protein electrophoresis, plasma hexosaminidase $\mathrm{A}$ and B levels, plasma and urinary amino acids, plasma lead and borrelia titres were all normal. The CSF was normal apart from minimal elevation of the protein level at $0.57 \mathrm{~g} / 1(0.2$ $0.5 \mathrm{~g} / \mathrm{l})$. Neurophysiological testing showed evidence of diffuse anterior horn cell dysfunction with the upper limb muscles being most severely affected.

The patient's neurological course was one of rapidly progressive deterioration and he died of respiratory failure 15 months after presentation.

Necropsy examination showed evidence of mild coronary and aortic atheroma. There was no evidence of recurrent carcinoma of the colon or colonic polyposis. Generalised limb muscle atrophy and thinning of the spinal anterior roots were observed. Significant grouped atrophy was found in limb, diaphragm and pharyngeal muscles. The external ocular muscles were normal. Sections of the motor cortex, other neocortical areas, hippocampus, cerebellum and midbrain showed no significant changes with conventional staining or ubiquitin immuno-cytochemistry (ICC). In the lower brainstem there was mild depletion of motor neurons in the facial and hypoglossal nuclei. There was marked depletion of lower motor neurons throughout the spinal cord (fig 1). Chromatolysis was observed in occasional neurons in the L4 and S1 segments. The neurons in the intermediolateral nucleus, Clarke's column and Onuf's nucleus appeared normal in number and morphology. An extensive study of multiple sections throughout the 


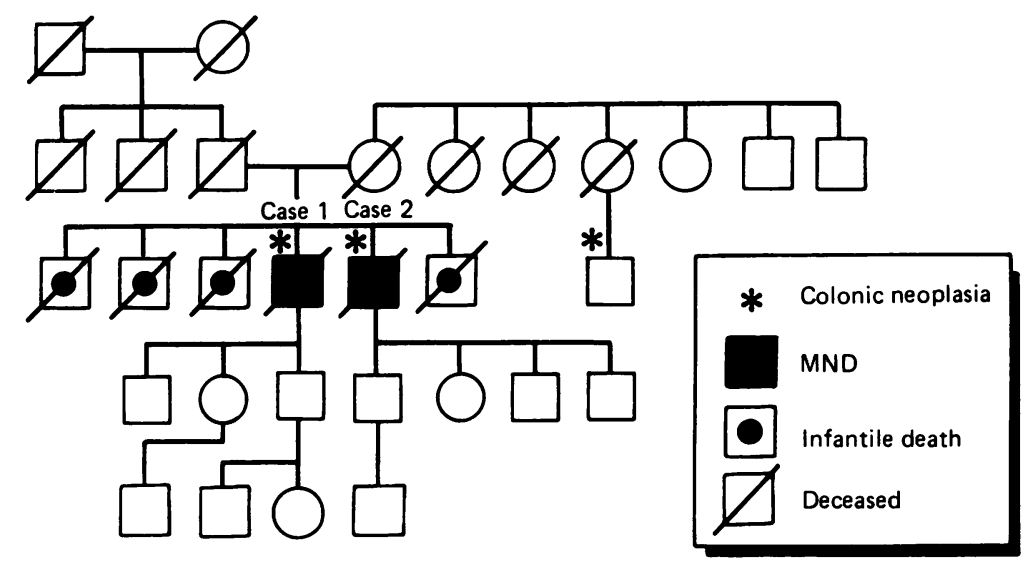

Figure 2 Available information in the family tree of our patients.

spinal cord using ubiquitin ICC showed no positive staining for $\mathrm{LMN}$ inclusion bodies in residual neurons. There were no significant white matter changes in the spinal cord and the corticospinal tract appeared normal at all levels.

Chromosomal analysis from both brothers showed no cytogenetic abnormality. In particular, the Giemsa band pattern of the long arm of chromosome 5 showed no evidence of deletion or paracentric inversion.

\section{Family history}

The family history was interesting in that four male siblings (three older and one younger than the patients) had all died between 1922-32, within the first few weeks of life. A review of the death certificates of these infants showed that no precise cause of death was established. All died at home and necropsies were not performed. In addition a male cousin on the maternal side had required surgery for carcinoma of the colon. The father of the two brothers died at the age of 76 of bronchopneumonia and the mother died at the age of 80 of uncertain cause. The two brothers have between them had a total of seven children and to date no neurological or gastro-intestinal problems have developed in this generation. The family tree is shown in fig 2 .

\section{Discussion}

An association between a familial predisposition to colonic neoplasia and a familial form of adult onset lower motor neuron degeneration has not previously been reported. The coexistence of the two diseases may represent a chance association, but there remains the possibility of genetic linkage between the two disorders. Whether any of the four infantile sibling deaths in this family resulted from genetic abnormalities remains unknown.

Interestingly, these two brothers had a purely LMN degenerative disorder, with no abnormalities in the motor cortex or pyramidal tracts. The neurological features in this family resemble previously reported cases of familial MND with only LMN involvement and a rapidly progressive clinical course. ${ }^{10}$ In our case at necropsy an atypical pathological find- ing was the absence of ubiquitinated inclusions in surviving motor neurons. ${ }^{11}$ In this regard the anterior horn cell pathology is more akin to childhood SMA than typical adult onset MND. It is possible that the familial adult onset motor neuron degeneration in our patients may represent a mild allelic variant of the earlier onset SMA syndromes, and may also be due to a defect on the long arm of chromosome 5. Attention is further directed to this chromosomal region by the occurrence of a familial tendency to colonic neoplasia in these two brothers, a defect which may represent a forme fruste of familial adenomatous polyposis coli which maps to the long arm of chromosome 5.

There have been several previous reports of associations between sporadic MND and gastro-intestinal neoplasia. Wechsler et al described a man of $\mathbf{4 2}$ years who developed amyotrophic lateral sclerosis (ALS) shortly after surgery for carcinoma of the colon and rectum. ${ }^{12}$ Lawyer and Netsky, in a report describing associated medical conditions in 53 MND cases, found malignant disease of the sigmoid colon in one case. ${ }^{13}$ Brain et al described 11 cases of MND occurring in the context of malignant disease, of whom two had carcinoma of the stomach and one had reticulum cell sarcoma of the ileum. ${ }^{14}$ Levy made the observation that parents of patients with MND exhibited a significantly higher incidence of carcinoma of the gastro-intestinal (GI) tract compared with parents of controls. ${ }^{15}$ This observation, however, was not confirmed by Vejjajura et al who observed that $5.5 \%$ of parents of MND cases and a similar percentage of parents of consecutive medical admissions died of GI cancer. ${ }^{16}$

Linkage analysis studies in familial adultonset MND have been few. Such studies pose difficulties because the late age of onset, combined with the short duration and usually fatal outcome of the disease, preclude the availability of multiple generations of affected individuals for testing. Siddique et al used 39 expressed and DNA markers and found no evidence of genetic linkage in six multigenerational ALS families. ${ }^{17}$ Chromosome 5 markers were not used in this study. The gene for $\mathrm{X}$-linked adult onset SMA has been mapped to the proximal long-arm of the $\mathrm{X}$ chromosome with significant linkage to the marker DXYS1. ${ }^{18}$

In the absence of recognised motor neuron pathology in other generations of this family at present, it is difficult to determine whether the mode of inheritance is autosomal dominant with reduced penetrance, new mutation autosomal dominant with gonadal mosaicism or autosomal recessive. The clinical features were not those of $\mathrm{X}$-linked bulbospinal neuronopathy. ${ }^{4}$

Three hypotheses may explain the association of the two diseases in this sibling pair. 1) The association of the $\mathrm{LMN}$ degenerative disorder with colonic neoplasia may represent the chance concurrence of two unlinked genetic disorders. 2) A single gene defect may have precipitated both disease processes. 3) The 
final explanation, which is of interest to those attempting to map both conditions, is that the same genetic event has brought about the development of both disorders. A simple deletion of chromosome 5 is excluded by the cytogenetic analysis, as is an inversion which could have disrupted genes at $5 \mathrm{q} 12$ and $5 \mathrm{q} 22$. The confidence limits for the location of the SMA and the adenomatous polyposis coli (APC) gene do not overlap. Recent recognition of a retarded male with familial APC and a deletion of $5 q 22-5 q 23$ (unpublished data: report in preparation) further excludes a contiguous gene defect. A second colonic cancer gene involved in a submicroscopic deletion at $5 q 12$ is a possibility. Chromosome 5 loss is well recognised in colonic cancer ${ }^{19}$ but there is no proof that this is the consequence of loss of the APC gene alone. The MND gene may be close to the APC gene though the patients so far reported with $\mathrm{APC}$ associated with $5 \mathrm{q}$ deletions have not shown evidence of LMN disease. ${ }^{2021}$

The combination of these diseases in two brothers suggests that linkage studies in familial adult-onset LMN degeneration should be directed initially to the vicinity of known colon neoplasia genes. In addition to the APC locus of chromosome 5q, other candidate regions would include $1.7 \mathrm{p} .13$ where the gene p53 has been implicated in the development of colorectal cancer $^{22}$ and $18 \mathrm{q} 21$ which is the site of the DCC (deleted in colonic cancer) gene..$^{23} 24$ Cell lines have been established from this sibling pair so that candidate genes may be evaluated in the future.

PJS is supported by the Wellcome Trust. We thank Mr Arthur Oakley for expert photographic assistance.

1 Kurland LT, Mulder DW. Epidemiologic investigations of amyotrophic lateral sclerosis. 2 Familial aggregation indicative of dominant inheritance. Neurology 1955;5: 182-268.
2 Mulder DW, Kurland LT, Offord KP, Beard M. Familial adult motor neuron disease/amyotrophic lateral sclerosis. Neurology 1986;36:511-17.

3 Williams DB, Floate DA, Leicester J. Familial motor neuron disease: differing penetrance in large pedigrees. $J$ Neurol Sci 1988;86:215-30.

4 Baraitser M. The genetics of neurological disorders. Oxford University Press, 1990:267-75.

5 Brzustowicz LM, Lehner T, Castilla LH, et al. Genetic mapping of chronic childhood-onset spinal muscular atrophy to chromosome 5q 11·2-13.3. Nature 1990;344: 540-1.

6 Melki J, Abdelhak S, Sheth P, et al. Gene for chronic proximal spinal muscular atrophies maps to chromosome proximal spinal muscular at

7 Gilliam TC, Brzustowicz LM, Castilla LH, et al. Genetic homogeneity between acute and chronic forms of spinal muscular atrophy. Nature 1990;345:823-5.

8 Nakamura Y, Lathrop M, Leppert M, et al. Localisation of the genetic defect in familial adenomatous polyposis within a small region of chromosome 5 . Am J Hum Genet 1988;43:638-44.

9 Leppert M, Burt R, Hughes JP, et al. Genetic analysis of an inherited predisposition to colon cancer in a family with a variable number of adenomatous polyps. New Eng J Med 1990;322:904-8.

10 Horton WA, Eldridge R, Brody JA. Familial motor neuron disease. Neurology 1976;26:460-5.

11 Leigh PN, Whitewell $\mathrm{H}$, Garofalo $\mathrm{O}$, et al. Ubiquitinimmunoreactive intraneuronal inclusions in amyotrophic lateral sclerosis: morphology, distribution and specificity. Brain 1991;114:775-88.

12 Wechsler IS, Sapirstein MR, Stein A. Primary and symptomatic amyotrophic lateral sclerosis. A clinical study of 81 cases. Am J Med Sci 1944;208:70-81.

13 Lawyer T, Netsky MG. Amyotrophic lateral sclerosis. A clinico-anatomic study of fifty-three cases. Arch Neurol Psychiat 1953;69:171-92.

14 Brain Lord, Croft PB, Wilkinson M. Motor neurone disease as a manifestation of neoplasm. Brain 1965;88:479-500.

15 Levy KM. Discussion on motor neuron disease: Genetic aspects. Proc Roy Soc Med 1962;55:1031.

16 Vejiajiva A, Foster JB, Miller H. Motor neuron disease. A clinical study. J Neurol Sci 1967;4:299-314.

17 Siddique T, Pericak-Vance MA, Brooks BR, et al. Linkage analysis in familial amyotrophic lateral sclerosis. Neurology 1989;39:919-25.

18 Fischbeck KH, Ionasescu V, Ritter AW, et al. Localisation of the gene for $X$-linked spinal muscular atrophy. Neurology 1986;36:1595-8.

19 Solomon E, Voss R, Hall V, et al. Chromosome 5 allele loss in human colorectal carcinoma. Nature 1987;328:616-9.

20 Herrera L, Kakati S, Gibas L, Pietrzak E, Sandberg AA. Gardner syndrome in a man with interstitial deletion of 5q. Am J Med Genet 1986;25:473-6.

21 Hockey KA, Mulcahy MT, Montgomery P, Levitt S. Deletion of chromosome $5 \mathrm{q}$ and familial adenomatous polyposis. J Med Genet 1989;26:61-8.

22 Vogelstein B, Fearon ER, Kern SE, et al. Allelotype of colorectal carcinomas. Science 1989;244:207-11.

23 Bowman BM, Wildrick DM, Alfard SR. Chromosome 18 allele loss at the D18S6 locus in human colorectal carcinomas. Biochem Biophys Res Commun 1988;155:463-9.

24 Solomon E. Colorectal cancer genes. Nature 1990;343: 412-14. 